\title{
Nuestra reputación online
}

\section{Our reputation on line}

El surgimiento de Internet y las redes sociales como Twitter, Facebook, Google y Blogs independientes, han sido de gran utilidad para muchos cirujanos que los han usado como herramientas para promocionar sus prácticas y realizar ofertas al público. Sin embargo, el anonimato y la gran difusión de estos vehículos, puede acarrear enormes problemas para uno de los valores más importantes que pueda tener un cirujano: su reputación.

Efectivamente, como en el lejano oeste, estas redes sociales ponen escasas restricciones a quienes quieren atacar y ofrecen mínimas herramientas a quienes quieren defenderse de estos ataques, existiendo nula legislación al respecto. Actualmente, cualquier persona con un computador y acceso a internet puede atacar la reputación de un cirujano. $Y$ estas frases posteadas, veraces o no, permanecerán en forma perpetua y serán regurgitadas una y otra vez por los motores de búsqueda alrededor del mundo.

La opción más simple para combatir estas publicaciones ponzoñosas puede ser simplemente ignorarlas. Especialmente cuando el cirujano las encuentra infundadas y no tiene el tiempo ni las ganas de entrar en terrenos hostiles. Sin embargo, esta actitud pasiva frente a estos asaltos en línea puede significar una falta de visión con resultados potencialmente desastrosos. El impacto de Internet en cuanto a atraer o rechazar potenciales pacientes es enorme, y en la actualidad no se puede subvalorar su alcance y popularidad. Sitios en Internet dedicados a la evaluación de médicos en USA, doblan su tráfico año a año. Por ejemplo, el sitio healthgrades.com tiene 6 millones de visitas nuevas al mes. Y lo que parece más importante, estos rankings online son muy apetecidos por los consumidores, a los motores de búsqueda les fascinan, y en ningún caso van a desaparecer.

Así como cuando quiere viajar puede ver los rankings de los hoteles donde se va a hospedar, ahora el potencial paciente puede ver cuán bueno es el cirujano que lo va a operar. Estos sistemas de rankings se han ido convirtiendo progresivamente en la principal fuente que los consumidores usan para buscar información acerca de una persona, lugar o cosa. Específicamente, los pacientes buscan información sobre el cirujano y su consulta para poder tomar una decisión racional y elegir entre distintos profesionales. La posibilidad de elegir entrega poder al paciente y, supuestamente, activa los mecanismos de competencia mediante el cual los distintos proveedores de salud intentarán mejorar su servicio para ser los elegidos. Pero la posibilidad de elegir dependerá de la calidad de la información que tenga el paciente, y su capacidad para interpretarla correctamente.

La libertad de expresión e información son fundamentos de la vida moderna, sin embargo, estos rankings tienen varios problemas en este sentido. Primero que todo, lo que realmente están midiendo es satisfacción del usuario, que en medicina no necesariamente refleja la calidad del servicio: un paciente puede salir muy contento porque siempre que va al médico le ordenan los últimos y más caros exámenes, pero definitivamente no está recibiendo una buena atención. En segundo lugar, el instrumento utilizado para medir a los cirujanos son los puntajes o las estrellas. Estas mediciones son subjetivas e imprecisas, ya que por un lado, lo que es una buena nota para alguien puede ser regular para otra persona, y por otro lado, definir realmente lo que es un buen cirujano requeriría de un instrumento muy complejo casi imposible de utilizar. Y en tercer lugar, la inteligencia colectiva podría decir que si cientos de personas evalúan a un cirujano, entre todos podría llegar a una evaluación más o menos certera. Lamentablemente esto no ocurre, y la mayoría de las veces hay 4 a 5 evaluaciones por médico. La mayoría positivas con escasa información y algunas negativas que no permitirían al paciente hacerse una real idea de la calidad humana y profesional del cirujano en cuestión.

Que el paciente tenga un espacio para poner su opinión en relación al servicio recibido y de esta forma informar a otros, es algo positivo para el consumidor siempre que sea en un marco de honestidad y respeto. 
EDITORIAL

Desafortunadamente algunos de ellos, enojados por el trato incumplido o cumplido en forma insuficiente, o por cualquier otro motivo, se convierten en críticos feroces que, sin dejar nada a su paso, dan rienda suelta a comentarios mordaces con desvaríos emocionales desproporcionados, protegidos por el anonimato y la falta de legislación. Son estos ataques dirigidos los que desvirtúan el sistema de ratings, confunden a la audiencia y dañan profundamente nuestra reputación.

¿Qué hacer entonces frente a comentarios negativos en contra nuestra en las redes sociales? De acuerdo a The Economist ("Fair Comment, posteado en línea el 5 de marzo de 2009), podría haber evidencia avalando los beneficios de revisiones mixtas. Ellos mencionan un estudio donde se demuestra que negocios con puras evaluaciones positivas estarían haciendo sólo marketing y serían desechados por los consumidores. La mejor combinación para impulsar la empresa sería muchas críticas positivas interrumpidas por una crítica negativa ocasional. En USA, algunos colegas han llegado a falsificar comentarios para revertir opiniones negativas de pacientes e incluso a hacerlos firmar cláusulas especiales que les impidan utilizar estos sitios. Creo que el cirujano jamás debe dejarse dominar por la frustración, ya que como cualquier ser humano, no puede tener una buena relación con todo el mundo. Necesitamos las críticas positivas pero también alguna negativa de tiempo en tiempo.

Tampoco es recomendable contestar directamente el "posteo" del paciente ya que eso podría iniciar una cascada de respuestas aún más negativas y por otro lado, se podría estar violando los derechos de privacidad al ventilar eventos protegidos por el secreto profesional. Podríamos iniciar una demanda por injurias o calumnias en el caso de que estas acusaciones online fueran un real atentado contra la dignidad del cirujano. Sin embargo, no hay ninguna referencia en la legislación acerca de estos delitos con publicidad en Internet, y además se debe considerar el costo económico y en tiempo que esto puede significar.

Si el cirujano tiene un sitio web, es aconsejable utilizarlo para informar a sus pacientes y contestar indirectamente algunas de las críticas negativas posteadas en la Web. Es de gran utilidad usar los testimonios espontáneos de pacientes contentos con nuestros servicios y colocarlos en nuestro sitio o pedirles que ellos mismos los coloquen en las redes sociales. Minimizar posibles reclamos a través de optimizar la eficiencia en la consulta es otra buena forma de prevenir ya que lo que ocurre en la oficina es una fuente frecuente de críticas negativas indirectas. Si la crítica es desmedida, es recomendable contactar directamente el sitio donde se publicó, explicarles el problema y solicitar amablemente su remoción. Muchas veces en estos casos los sitios comprenden la situación y acceden a retirar el post. Tampoco se aconseja creer en hackers que dicen poder eliminar todas las críticas negativas en su contra, ya que ellos mismos pueden ser los que las están escribiendo. Jamás tratar de esconderse y siempre dar la cara, porque lo que nos preocupa se viene y con mucha fuerza. Los buscadores de Internet están cada vez más sensibles e influenciados por estas "señales sociales”. Es ahí donde está el paradigma. Es fundamental monitorear Internet y Googlearse con frecuencia. Es importante entender que para cuidar la reputación, y contrarrestar eventuales ataques en su contra, debemos primero que nada saberlo.

\author{
Dr. Patricio Andrades C. \\ Cirujano Plástico \\ Hospital Clínico Universidad de Chile \\ Santiago, Chile
}

